Hidrólise Enzimática de Celulose para Obtenção de Glicose Utilizando Líquido lônico como Meio Solvente

\author{
Andrade, T. C. C.; Bitencourt, W. C.; Bomtempo, F. V. S.; Alves, F. S.; \\ Barbosa, R. S.; Guarda, E. A.
}

Rev. Virtual Quim., 2019, 11 (1), 310-325. Data de publicação na Web: 11 de fevereiro de 2019

http://rvq.sbq.org.br

\title{
Enzymatic Cellulose Hydrolysis for Glucose Obtainment Using lonic Liquid as a Solvent Medium
}

Abstract: Cellulose is one of the main constituents of the wall of a plant cell, and its complete hydrolysis produces glucose. Cellulases are the enzymes responsible for the degradation of cellulose. The condition in which such reactions usually develop occurs in organic solvents and water. In the present work the ionic liquids, substances that are completely constituted by ions and are in the liquid state at room temperature. The enzymes Cellic CTec2 and HTec2 (Noozymes ${ }^{\circledR}$ ) were used in the hydrolysis reactions of cellulose obtained from three types of biomass: sugarcane bagasse, elephantgrass and wood sawdust (red angelim). All the biomasses were submitted to a pretreatment so that the enzymes had greater accessibility to the cellulose. It was verified the existence of alterations caused by the presence of the ionic liquids in the hydrolysis reaction, being possible to affirm that the use of this methodology in the search of a more advantageous process to obtain glucose did not represent an increase in the glucose contents obtained after the hydrolysis. The most promising ionic liquid was the ([BMIM+] $\left.\left[\mathrm{BF}^{-}\right]\right)$interacted with sugarcane, reaching a yield of $57.7 \%$ for 72 hours of hydrolysis reaction.

Keywords: Lignocellulosic biomass; enzymatic hydrolysis; ionic liquids.

\section{Resumo}

A celulose é um dos principais constituintes da parede celular das plantas, sendo que sua hidrólise completa produz glicose. As celulases são as enzimas responsáveis pela degradação da celulose. A condição em que tal reação geralmente se desenvolve ocorre em solventes orgânicos e água. No presente trabalho foi utilizado como meio para a reação, os líquidos iónicos, substâncias que são completamente constituídas por íons e estão em estado líquido à temperatura ambiente. As enzimas Cellic CTec2 e HTec2 (Noozymes ${ }^{\circledR}$ ) foram utilizadas nas reações de hidrólise da celulose obtida a partir de três tipos de biomassas: bagaço de cana-de-açúcar, capim-elefante e serragem de madeira (angelim vermelho). Todas as biomassas foram submetidas a um pré-tratamento para que as enzimas tivessem maior acessibilidade à celulose. Verificou-se alterações causadas pela presença dos líquidos iónicos na reação de hidrólise, sendo possível afirmar que o uso desta metodologia na busca de um processo mais vantajoso para obter glicose não representou um aumento nos teores de glicose obtidos após a hidrólise. O líquido iônico mais promissor foi o $\left(\left[\mathrm{BMIM}^{+}\right][\mathrm{BF} 4-]\right)$ na interação com a celulose obtida da cana-de-açúcar, atingindo um rendimento de $57,7 \%$ durante 72 horas de reação.

Palavras-chave: Biomassa lignocelulósica; hidrólise enzimática; liquidos iônicos.

\footnotetext{
* Universidade Federal do Tocantins, Departamento de Química, Campus de Palmas, CEP 77001-090, Palmas-TO, Brasil.

M coelho.ambiental@gmail.com

DOI: $10.21577 / 1984-6835.20190022$
} 


\title{
Hidrólise Enzimática de Celulose para Obtenção de Glicose Utilizando Líquido lônico como Meio Solvente
}

\section{Thaysi C. C. Andrade, * Waldo C. Bitencourt, Fabrícia V. S. Bomtempo, Filipe S. Alves, Robson S. Barbosa, Emerson A. Guarda}

\author{
Universidade Federal do Tocantins, Departamento de Química, Campus de Palmas, \\ CEP 77001-090, Palmas-TO, Brasil. \\ * coelho.ambiental@gmail.com
}

\section{Introdução}

\section{Materiais e Métodos}

2.1. Preparação das amostras

2.2. Determinação do teor de lignina

2.3. Determinação do teor de celulose

2.4. Pré-tratamento químico

2.5. Síntese dos líquidos iônicos

2.6. Hidrólise enzimática

2.7. Quantificação da glicose

2.8. Análise estatística

\section{Resultados e Discussões}

3.1. Determinação do teor de celulose e lignina

3.2. Determinação de glicose e rendimento da hidrólise enzimática

3.3. Regressão polinomial

\section{Conclusão}

\section{Introdução}

Diante da tendência do esgotamento das fontes de combustíveis fósseis a busca por fontes energéticas renováveis foi impulsionada nas últimas décadas, surgindo assim dentre outros, os biocombustíveis líquidos de segunda geração. Por esta razão, diferentes tecnologias de pré-tratamento, sacarificação (ou hidrólise) e fermentação vêm sendo estudadas em todo mundo para demonstrar a viabilidade comercial deste processo. ${ }^{1}$ Neste sentido, a maior parte destes estudos está orientada ao aumento da acessibilidade química da celulose, buscando reduzir a quantidade de enzimas necessárias para a conversão dos polissacarídeos em açúcares fermentescíveis. ${ }^{2}$

Devido à natureza recalcitrante da biomassa, a hidrólise enzimática é muito lenta 
e é difícil atingir elevados rendimentos em açúcar se a biomassa não for previamente prétratada. O pré-tratamento é provavelmente a etapa mais crucial, uma vez que tem forte impacto em todas as outras etapas do processo, por exemplo, na hidrólise enzimática e na fermentação, em termos de digestibilidade da celulose e toxicidade da fermentação. ${ }^{3}$

O pré-tratamento é considerado um dos processos mais importantes para a produção de biocombustíveis, com a função de aumentar a área de superfície da biomassa modificando as microfibras de celulose, ou seja, reduzindo sua cristalinidade, removendo hemicelulose e lignina, para torná-la digerível pelas enzimas. A modificação nas características estruturais da matriz lignocelulolítica pode ser realizada por vários tipos de pré-tratamento, os quais são classificados em físico, químico, físico-químico e biológico. ${ }^{4}$ Tendo em vista que o foco deste trabalho não é o pré tratamento, todas as biomassa passaram pelo mesmo tipo de prétratamento combinado.

Atualmente, vários processos industriais empregam enzimas em diferentes meios, inclusive na presença de solventes orgânicos. Uma das principais vantagens na utilização de enzimas como catalisadores é a seletividade observada nas reações. Isto ocorre, devido à preferência elevada por um determinado substrato, ou seja, à capacidade de reconhecer a estrutura de moléculas, além de permitir a execução de processos em condições mais suaves de reação com excelente controle e eficiência do processo. Os líquidos iônicos (LIs), por sua vez, são uma das classes de compostos mais promissores, considerados "solventes verdes", mostrandose excelentes substitutos para os solventes orgânicos. $\mathrm{O}$ diferencial está na possibilidade de moldagem de suas propriedades de acordo com as necessidades da reação, sendo os LIs imidazólios os mais importantes e utilizados na atualidade. ${ }^{5}$ A possível vantagem da utilização de enzimas em LI pode ser atribuída ao fato de que a combinação destes materiais favorece o aumento da atividade enzimática, quando comparado aos solventes orgânicos convencionais, que inibem a atividade catalítica, ${ }^{6}$ tendo em vista que os Lls agem como um suporte eficiente da enzima nanoorganizando o sistema. ${ }^{7}$

No presente trabalho foram avaliados os efeitos dos LIs ([BMIM $\left.{ }^{+}\right]$[Br-]), ([BMIM $\left.{ }^{+}\right]$ $\left.\left[\mathrm{H}_{3} \mathrm{CCOO}-\right]\right)$, e ([BMIM$\left.\left.{ }^{+}\right]\left[\mathrm{BF}_{4}^{-}\right]\right)$na reação de hidrólise enzimática de celulose obtida de três tipos de biomassa - bagaço de cana-de-açúcar, capim-elefante e serragem de Angelim vermelho - para obtenção de glicose. As biomassas foram submetidas à um prétratamento combinado, empregando-se uma etapa física e uma química (meio ácido e básico). $O$ parâmetro utilizado para avaliar o efeito da presença dos LIs sobre a hidrólise enzimática foi o rendimento de glicose obtida.

\section{Materiais e Métodos}

As biomassas utilizadas neste trabalho foram: cana-de-açúcar (Saccharum officinarum L.), capim-elefante (Pennisetum purpureum), e serragem de madeira (Dinizia excelsa Ducke). Foi realizado a determinação do teor de celulose e lignina das biomassas antes e após o pré-tratamento.

$O$ delineamento experimental utilizado foi inteiramente casualizado representado por seis tratamentos e três repetições. Os tratamentos foram dispostos em esquema de parcela subdividida, onde nas parcelas foram alocadas as biomassas e nas subparcelas o pré-tratamento e biomassas in natura.

\subsection{Preparação das amostras}

As biomassas foram desidratadas em estufa a $65{ }^{\circ} \mathrm{C}$ até peso constante visando a remoção da umidade, trituradas em moinho de facas com peneiras de $1 \mathrm{~mm}$ de diâmetro e mantidas em dessecador até o momento das análises. Esse tipo de preparo foi realizado em todas as biomassas, antes de se determinar o teor de celulose e lignina. 


\subsection{Determinação do teor de lignina}

O teor de lignina foi estimado com base nos procedimentos realizados na literatura, com adaptações. ${ }^{8}$ As análises foram realizadas em triplicata para cada biomassa. Após pesadas $1 \mathrm{~g}$ das amostras, moídas e secas, foram colocadas em um tubo de ensaio e adicionados $17 \mathrm{~mL}$ de ácido sulfúrico $72 \%$. Após 15 min de agitação vigorosa, digeriu-se as amostras por $24 \mathrm{~h}$. Posteriormente adicionou-se $306 \mathrm{~mL}$ de água destilada para diluir o ácido sulfúrico a $4 \%$ e transferiu-se o conteúdo para um balão que foi mantido sob aquecimento e refluxo por $4 \mathrm{~h}$.
Após o refluxo as amostras foram filtradas a vácuo, sendo lavadas com água destilada, sob agitação constante, para evitar perda de biomassa. O sólido recolhido no funil foi enxaguado com água destilada até que se obtivesse $\mathrm{pH}$ próximo à neutralidade. Após o funil foi levado à estufa a $105{ }^{\circ} \mathrm{C}$ e seco até adquirir peso constante. Após secagem e estabilização a temperatura ambiente, pesouse a massa total e finalmente o conjunto foi levado ao forno mufla a $550{ }^{\circ} \mathrm{C}$ a fim de obter o teor de cinzas, conforme observado nas Equações 1 e 2:

$$
\begin{aligned}
& \text { Teor de Cinzas } \%=\left(\frac{\mathrm{MFC}-\mathrm{MF}}{\mathrm{MA}}\right) \times 100 \\
& \text { Teor de Lignina } \%=\left(\frac{\mathrm{MFL}-\mathrm{MF}}{\mathrm{MA}} \times 100\right)-\mathrm{TC} \%
\end{aligned}
$$

Onde:

MF: massa do funil limpo e seco;

MA: massa da amostra;

MFL: massa do funil + lignina (após secagem em estufa);

MFC: massa do funil + cinzas (após calcinação em mufla);

TC\%: teor de cinzas.

\subsection{Determinação do teor de celulose}

As análises foram realizadas em triplicata para cada biomassa, de acordo com a literatura. ${ }^{9,10}$ Após pesadas $1 \mathrm{~g}$ de amostra, moídas e secas, a estas foi adicionado reagente ácido $(72,73 \%$ de ácido acético glacial, 18,18 \% de água destilada e 9,09 \% de ácido nítrico concentrado) em um tubo de ensaio. A mistura foi levada a banho-maria por $30 \mathrm{~min}$ para digestão. Após, adicionou-se álcool etílico aos tubos, filtrou-se a vácuo e o sólido foi lavado com etanol quente, tolueno quente e, finalmente, com éter sulfúrico quente. Em seguida, o material (amostra e papel de filtro) foi transferido para um cadinho previamente calcinado. Esse sistema foi levado à estufa a $105^{\circ} \mathrm{C}$ para secar durante 4 h. Depois de transcorrido o tempo, o conjunto (cadinho + celulose + minerais + papel de filtro) foi pesado e incinerado em forno mufla a $550{ }^{\circ} \mathrm{C}$. Foi possível determinar o percentual de celulose aplicando-se a Equação 3:

$$
\text { Celulose } \%=\frac{[(M i-P-M f)] x 100}{m A}
$$


Onde,

$\mathrm{Mi}=$ massa do cadinho + papel + amostra;

$P=$ massa do papel de filtro (papel quantitativo);

$\mathrm{Mf}=$ massa do cadinho+ cinzas;

$\mathrm{mA}=$ massa da amostra.

\subsection{Pré-tratamento químico}

Segundo a metodologia, ${ }^{11}$, as biomassas foram pré-tratadas, em autoclave a $121^{\circ} \mathrm{C}$ por $15 \mathrm{~min}$, utilizando $100 \mathrm{~g}$ de biomassa (base seca) com $2 \mathrm{~L}$ de solução de hidróxido de sódio a $4 \%, 1: 20(\mathrm{~m} / \mathrm{v})$. O material obtido foi levado a pH 2,0 por 30 min utilizando ácido fosfórico (p.a), e logo neutralizado com hidróxido de sódio. Filtrou-se e em seguida um volume proporcional de água destilada foi adicionado ao volume do material sólido lignocelulolítico e essa mistura foi novamente autoclavada a $121^{\circ} \mathrm{C}$ por $15 \mathrm{~min}$. A suspensão foi filtrada e o material sólido desidratado na estufa a $65^{\circ} \mathrm{C}$ até massa constante, obtendo assim a biomassa seca pré-tratada.

Após o pré-tratamento químico determinou-se novamente o teor de celulose e lignina das biomassas, tornando-se possível constatar as modificações proporcionadas pelo pré-tratamento.

\subsection{Síntese dos líquidos iônicos}

A síntese dos líquidos iônicos seguiu metodologia previamente desenvolvida. ${ }^{12}$

Brometo de 1-n-butil-3-metil-imidazol ([BMIM+] [Br] $]$ : : A síntese do brometo de 1-nbutil-3-metil-imidazol $\left(\left[\mathrm{BMIM}^{+}\right] \quad[\mathrm{Br}]\right), \quad$ foi realizada com a mistura de $n$-bromo-butano e 1-metil-imidazol adicionados na razão molar de 1,1:1 em um balão de fundo chato sob agitação por $48 \mathrm{~h}$ em temperatura ambiente. Após o tempo de reação foi obtido o LI.
Acetato de 1-n-butil-3-metil-imidazol ([BMIM $\left.\left.{ }^{+}\right]\left[\mathrm{H}_{3} \mathrm{CCOO}-\right]\right): \mathrm{O}$ ([BMIM $\left.{ }^{+}\right]\left[\mathrm{Br}^{-}\right]$) obtido em etapa anterior foi misturado com acetato de sódio na razão molar de 1:1 na presença de clorofórmio. A reação foi conduzida por $24 \mathrm{~h}$ a $40{ }^{\circ} \mathrm{C}$ sob agitação. Após o término da reação o acetato de 1-n-butil-3-metil-imidazol ([BMIM $\left.\left.{ }^{+}\right]\left[\mathrm{H}_{3} \mathrm{CCOO}\right]\right)$ formado foi lavado com éter etílico por três vezes, sendo seco sob vácuo. $\mathrm{O}$ produto resultante é um líquido viscoso, amarelado.

Tetraflourborato de 1-n-butil-3-metilimidazol ([BMIM $\left.\left.{ }^{+}\right]\left[\mathrm{BF}_{4}^{-}\right]\right):$A síntese do $\left(\left[\mathrm{BMIM}^{+}\right]\left[\mathrm{BF}_{4}^{-}\right]\right)$foi realizada com a mistura de n-bromo-butano, 1-metil-imidazol e Tetrafluoborato de sódio (98\%) adicionados na razão molar de 1:1:1 na presença de clorofórmio em um balão de fundo chato sob agitação por $24 \mathrm{~h}$ a $40{ }^{\circ} \mathrm{C}$. Após o tempo de reação foi obtido o LI. O solvente foi extraído sob vácuo, em seguida o LI foi lavado três vezes com éter etílico e posteriormente secado novamente sob vácuo para retirar solvente remanescente.

A obtenção dos LIs foi confirmada por espectrometria de infra vermelho com transformada de Fourie (FT-IR) em espectrômetro Agilent Cary 630 FTIR.

\subsection{Hidrólise enzimática}

A hidrólise enzimática foi realizada com 0,1 $\mathrm{g}$ de amostra de cada biomassa, sendo avaliada separadamente na presença de cada um dos Lls em suspensão. Foi utilizado $6,0 \mathrm{~mL}$ de solução tampão citrato $(\mathrm{pH} 5,0)$ e $1,5 \mathrm{~mL}$ de $\mathrm{LI}$, visando manter o $\mathrm{pH}$ entre 4,5 a 5,5, faixa de maior rendimento da enzima. As condições de reação foram de $72 \mathrm{~h}$ entre 50 a $55^{\circ} \mathrm{Ce} 150$ rotações por minuto, empregando uma mistura de $12 \mu \mathrm{L}$ da enzima celulase comercial (10 $\mu \mathrm{L}$ da Cellic CTec2 e $2 \mu \mathrm{L}$ da Cellic HTec2), conforme orientação do fabricante. Tais enzimas são classificadas como um complexo de celulases agressivas (com alto percentual de $\beta$-glucosidase e hemicelulase) que visa obter açúcar fermentescível. A liberação de 
glicose durante $\mathrm{o}$ processo hidrolítico foi monitorada nos tempos de 12, 24, 48 e $72 \mathrm{~h}$, retirando-se alíquotas da reação, que foram centrifugadas e filtradas em membrana de nylon de $0,2 \mu \mathrm{m}$. As alíquotas foram avaliadas em seu teor de glicose por cromatografia líquida de alta eficiência. O monitoramento do processo hidrolítico também foi realizado para as biomassas sem a condição de prétratamento e sem a presença de LI.

\subsection{Quantificação da glicose}

A determinação de glicose foi realizada por Cromatografia Líquida de Alta Eficiência (CLAE), utilizando-se equipamento da marca Shimadzu (LC-10 Series Avp; desgaseificador: DGU-14A, integrador: CLASS LC-10), com eluição isocrática, pelo bombeamento (LC$10 A D)$ de uma fase móvel composta de $5 \mathrm{mM}$ de ácido sulfúrico em água ultrapura (destilada e deionizada). $O$ fluxo do eluente foi de $0,6 \mathrm{~mL} \mathrm{~min}$, a $35^{\circ} \mathrm{C}$ (forno de coluna CTO-

$$
\mathrm{RH}(\%)=\frac{[\text { Gli. }]}{[\text { Cel. }]} 0,9 \times 100
$$

\section{Sendo:}

$\mathrm{RH}(\%):$ rendimento da hidrólise;

[Gli.]: concentração de glicose da biomassa (g L);

[Cel.]: concentração de celulose da biomassa ( $\mathrm{g} \mathrm{L}$ );

0,9: fator de conversão da celulose.

\subsection{Análise estatística}

Para os dados referente à fase de prétratamento e hidrólise enzimática realizou-se análise de variância e as médias foram comparadas pelo teste Scott Knott a $5 \%$ de significância. Para os tempos foram realizadas análises de regressão através do uso de polinômios ortogonais e uma vez estabelecida
10A), com corrida de tempo total de $25 \mathrm{~min}$, com detector de índice de refração (Shimadzu, modelo RID-10A). Uma alíquota de $20 \mu \mathrm{l}$ da amostra foi injetada manualmente (injetor Rheodyne - iL malha 20) em coluna de exclusão iônica da marca Phenomenex Rezex ROA-Organic Acid $\mathrm{H}+(300 \times 7,8 \mathrm{~mm})$ com conexão direta a um cartucho de segurança Phenomenex Carbo-H ( $4 \times 3 \mathrm{~mm})$ preenchida com material semelhante ao da coluna principal.

Foi determinado o teor de glicose, já que este é o carboidrato fermentescível majoritariamente oriundo da celulose.

Considerando o total de celulose na amostra e sua massa inicial, foi possível calcular o rendimento das reações de hidrólise. Para isso, tomaram-se os valores máximos obtidos da concentração de glicose e o fator de conversão de glicose em celulose. $^{13,14,15}$

Os cálculos do rendimento da hidrólise foram realizados pela seguinte equação:

a relação funcional entre os tempos e o rendimento foi determinada equação de regressão. As análises estatísticas foram realizadas pelo software Sisvar 5.6 e as curvas de regressão pelo software Origin 2017.

$O$ delineamento experimental utilizado foi inteiramente casualizado representado por seis tratamentos e três repetições. Os tratamentos foram dispostos em esquema de parcela subsubdividida, onde nas parcelas foram alocadas as três biomassas (cana-deaçúcar, capim-elefante e serragem), na subparcela as cinco reações de hidrólise (com biomassa in natura sem LI, com biomassa prétratada sem LI, e com biomassa pré-tratada na presença dos Lls $\left(\left[\mathrm{BMIM}^{+}\right][\mathrm{Br}]\right)$, ([BMIM $\left.{ }^{+}\right]$ $\left.\left[\mathrm{H}_{3} \mathrm{CCOO}^{-}\right]\right), \quad$ e $\quad\left(\left[\mathrm{BMIM}^{+}\right] \quad\left[\mathrm{BF}_{4}^{-}\right]\right)$ respectivamente), e na subsubparcela os tempos de reação $(12,24,48$ e 72 h). 


\section{Resultados e Discussões}

\subsection{Determinação do teor de celulose e lignina}

Os resultados experimentais da composição química das biomassas lignocelulósicas indicaram a necessidade de desdobramento dos fatores (Tabela 1), sendo atendida a distribuição da curva normal.

Os coeficientes de variação para as parcelas (CV 4.9) e subparcelas (CV 5.2) para celulose foram baixos, assim como para as parcelas e subparcelas da lignina (CV 7.4) e (CV $10)$, indicando boa precisão do experimento.

Quando avaliado o teor de celulose, o comparativo entre as biomassas in natura prétratadas revelou que houveram respostas diferentes de cada biomassa ao mesmo prétratamento. O capim-elefante e a serragem in natura não apresentam diferença significativa no teste Scott Knott a um nível de $5 \%$, porém mostraram teor de celulose superiores à canade-açúcar. Além disto, após o teste, as três biomassas não apresentaram diferença significativa entre si depois de pré-tratadas. A Tabela 2 apresenta os valores das médias de teor de celulose das biomassas in natura e pré-tratadas.

Tabela 1. Resumo da análise de variância das biomassas e pré-tratamento quanto ao teor de celulose e lignina

\begin{tabular}{cccc}
\hline FV & GL & QM de celulose & QM de lignina \\
\hline Biomassas & 2 & $58.58364^{*}$ & $214.83783^{*}$ \\
Resíduo a & 9 & 8.74675 & 1.22227 \\
Pré-tratamento & 1 & $84.90082^{*}$ & $404.42460^{*}$ \\
Interação BM x PT & 2 & $189.70290^{*}$ & $10.54449^{*}$ \\
Resíduo b & 9 & 10.01506 & $2.20701 \backslash$ \\
Total & 23 & & \\
\hline
\end{tabular}

FV - Fontes de variação; GL - Grau de liberdade; QM - Quadrado médio; *Significativo a 5 \% de significância pelo teste $F$

Tabela 2. Médias do teor de celulose das biomassas in natura e pré-tratadas

\begin{tabular}{ccc}
\hline Biomassa & In natura (\%) & Pré-tratada (\%) \\
\hline Cana-de-açúcar & $53.7675 \mathrm{bB}$ & $60.3400 \mathrm{aA}$ \\
Capim-elefante & $63.5775 \mathrm{aA}$ & $58.4900 \mathrm{aB}$ \\
Serragem & $68.6050 \mathrm{aA}$ & $55.8350 \mathrm{aB}$ \\
\hline
\end{tabular}

Média seguida de pelo menos uma mesma letra maiúscula na linha e minúscula na coluna, são estatisticamente iguais a 5 \% de significância pelo teste Scott Knott

Para a cana-de-açúcar a disponibilidade da celulose foi $12,2 \%$ maior após o prétratamento devido ao rompimento das fibras de lignina e hemicelulose na parte interna da biomassa e a dissolução desta no ácido do pré- tratamento. Este fato que não se repete para o capim elefante e serragem em que ocorreu redução na disponibilidade de celulose da ordem de $8 \%$ e $18,6 \%$ respectivamente. Isto pode ser atribuído a presença dos ácidos no 
pré-tratamento químico, que dependendo da concentração podem causar degradação da celulose, já que a utilização de ácidos também é utilizada como uma rota para realização de hidrólise direta. ${ }^{16}$ Apesar disso sabe-se que a concentração adequada de ácido utilizada no processo auxilia na retirada da hemicelulose e deslignificação das biomassas. ${ }^{1}$ Todavia, a hidrólise ácida da hemicelulose é similar à da celulose, podendo-se também afirmar que para o capim elefante e serragem, o prétratamento aplicado não seja o mais adequado para retirada de hemicelulose, tendo em vista que provocou também a perda de celulose. ${ }^{16}$

Embora estatisticamente o teor de celulose das biomassas foram alterados, com o pré-tratamento, diversos autores afirmam que a degradação da celulose só começa a se tornar importante em temperaturas em torno de $220{ }^{\circ} \mathrm{C} .{ }^{16-18}$

Os valores obtidos para o percentual do teor de celulose das biomassas in natura se mostraram similares à faixa reportada em outros trabalhos, como o bagaço de cana-deaçúcar, em torno de 32 a $45 \%{ }^{9,19-21}$ e serragem de madeira, em torno de 37 a 62 $\%^{22,23}$ Para o capim elefante o valor obtido ficou superior à faixa reportada em outros trabalhos onde os valores variam entre 30 a $40,7 \% .{ }^{24,25}$

A Tabela 3 apresenta os valores das médias de teor de lignina das biomassas in natura e pré-tratadas.

Tabela 3. Médias do teor de lignina das biomassas in natura e pré-tratadas

\begin{tabular}{ccc}
\hline Biomassa & In natura (\%) & Pré-tratada (\%) \\
\hline Cana-de-açúcar & $22.7850 \mathrm{aA}$ & $12.1800 \mathrm{bB}$ \\
Capim-elefante & $12.8725 \mathrm{bA}$ & $4.8750 \mathrm{cB}$ \\
Serragem & $21.1900 \mathrm{aA}$ & $15.1625 \mathrm{aB}$ \\
\hline
\end{tabular}

Média seguida de pelo menos uma mesma letra maiúscula na linha e minúscula na coluna, são estatisticamente iguais a 5 \% de significância pelo teste Scott Knott

De acordo com o teste de média, in natura, - capim - elefante foi diferente estatisticamente a um nível de $5 \%$ de significância da cana e da serragem apresentando o menor teor de lignina que os demais. Após o pré tratamento todas a biomassas foram diferentes estaticamente, sendo observado que em ambas houve uma redução no teor de lignina após o pré tratamento. Analisando-se cada biomassa separadamente, o capim elefante antes e após o pré-tratamento é a biomassa que apresentou menor teor de lignina.

O percentual de lignina observado nas biomassas sem pré-tratamento se mostrou similar aos observados na literatura para todas as biomassas avaliadas, 19 a $24 \%$ para o bagaço de cana-de-açúcar, ${ }^{19} 8,26$ a $10,9 \%$ para o capim elefante, ${ }^{25}$ e 26,4 a $31,77 \%$ para a serragem. ${ }^{23,26}$ A Tabela 4 apresenta os valores do teor de celulose e lignina para as biomassas in natura e pré-tratadas. 
Tabela 4. Quantificação do teor de celulose e lignina para as biomassas in natura e prétratadas

\begin{tabular}{ccccc}
\hline \multirow{2}{*}{ Biomassa } & \multicolumn{2}{c}{ Celulose } & \multicolumn{2}{c}{ Lignina } \\
\cline { 2 - 5 } & In natura & Pré-tratada & In natura & Pré-tratada \\
\hline Cana-de-açúcar & $53,772 \pm 1,58$ & $60,342 \pm 4,27$ & $22,789 \pm 2,15$ & $12,184 \pm 1,09$ \\
\hline Capim-elefante & $63,581 \pm 1,39$ & $58,493 \pm 1,78$ & $12,874 \pm 1,05$ & $4,879 \pm 0,35$ \\
\hline Serragem & $68,616 \pm 4,95$ & $55,839 \pm 2,42$ & $21,198 \pm 1,36$ & $15,169 \pm 1,17$ \\
\hline
\end{tabular}

Parte da fração de hemicelulose foi removida no pré-tratamento alcalino, uma vez que os pré-tratamentos alcalinos são geralmente mais eficazes na solubilização de uma maior fração da lignina, deixando parte da hemicelulose insolúvel, sendo esse um dado importante, caso o passo seguinte após o pré-tratamento seja a hidrólise enzimática, uma vez que favorece a reatividade da celulose, que pode ser significativamente aumentada. ${ }^{27}$

Dessa forma pode-se inferir que o prétratamento combinado (ácido e básico) foi favorável para a redução no teor de lignina podendo ser aplicado às três biomassas, o que representa uma vantagem, tendo em vista que a lignina se constitui como uma "barreira" que impede a eficiência da hidrólise enzimática. A redução no teor de lignina das biomassas foi da ordem de $46,53 \%$ para a cana-de-açúcar, $28,45 \%$ para a serragem e $62,16 \%$ para o capim-elefante.

3.2. Determinação de glicose e rendimento da hidrólise enzimática

Foi determinada interação significativa para os diferentes tipos de biomassa, diferentes reações de hidrólise e o tempo de reação, indicando que os efeitos isolados dos fatores não explicam toda a variação encontrada no rendimento da hidrólise enzimática, sendo realizado os desdobramentos e atendida a distribuição da curva normal (Tabela 5).
Na Tabela 6 é apresentado a média do rendimento de glicose para as diferentes reações de hidrólise realizadas. Avaliando-se cada biomassa separadamente e os mesmos tempos dentro das diferentes reações de hidrólise, observa-se que para a cana-deaçúcar o tempo de $12 \mathrm{~h}$ apresenta melhor desempenho quando pré-tratada sem a presença de LI. Na presença de LI, o melhor resultado foi a interação com o $\left(\left[\mathrm{BMIM}^{+}\right]\left[\mathrm{BF}_{4}^{-}\right.\right.$ ]), sendo que da interação com os outros dois LI e sem pré tratamento os resultados são igualmente inferiores. Para o tempo de $24 \mathrm{~h}$ de reação o melhor resultado permaneceu sendo para a hidrólise com biomassa prétratada, seguida da interação com o ([BMIM $\left.{ }^{+}\right]$ $\left.\left[\mathrm{BF}_{4}{ }^{-}\right]\right)$. O resultado da interação com $\mathrm{O}$ ([BMIM $\left.\left.{ }^{+}\right]\left[\mathrm{H}_{3} \mathrm{CCOO}^{-}\right]\right)$é considerado igual quando a biomassa é sem pré-tratamento, ficando a interação com o ([BMIM $\left.\left.{ }^{+}\right]\left[\mathrm{Br}^{-}\right]\right) \mathrm{com}$ o pior desempenho. $O$ desempenho para o tempo de 48 e $72 \mathrm{~h}$ acompanha os anteriores quanto à biomassa pré-tratada sem a presença de $\mathrm{LI}$ e quando interagindo com o ([BMIM+] $\left.\left[\mathrm{BF}_{4}^{-}\right]\right)$.

Para o capim elefante quando o tempo de reação é de 12 e $24 \mathrm{~h}$ os rendimentos de hidrólise são considerados iguais para a biomassa in natura e pré-tratada, sendo que para as outras três interações com LI os resultados foram considerados inferiores. Quando avaliado os tempos de 48 e $72 \mathrm{~h}$ de reação a biomassa pré-tratada sem a presença de LI obtêm o melhor desempenho, seguida pela biomassa in natura. Os resultados com os LIs foram igualmente inferiores. 
Tabela 5. Resumo da análise de variância relacionando as biomassas, as diferentes reações de hidrólise e o tempo de reação

\begin{tabular}{lcc}
\hline \multicolumn{1}{c}{ FV } & GL & QM \\
\hline \multicolumn{1}{c}{ Biomassas } & 2 & $4567,339937^{*}$ \\
Reações de hidrólise enzimática & 4 & $6117,562706^{*}$ \\
Tempo & 3 & $1083,564343^{*}$ \\
Biomassas x Reações de hidrólise enzimática & 8 & $1606,889237^{*}$ \\
Biomassas x Tempo & 6 & $45,799037^{\text {ns }}$ \\
Reações de hidrólise enzimática x Tempo & 12 & $248,902680^{*}$ \\
Biomassas x Reações de hidrólise enzimática x & 24 & $57,074412^{*}$ \\
Tempo & & 12,253779 \\
Erro 1 & 6 & 7,325913 \\
Erro 2 & 24 & 15,111410 \\
Erro 3 & 90 & \\
CV 1 (\%) & 14,41 & \\
CV 2 (\%) & 11,14 & \\
CV 3 (\%) & 16,00 & \\
Média geral & 24,2982778 & \\
\hline
\end{tabular}

FV: Fontes de variação; GL: Grau de liberdade; QM: Quadrado médio; * e ns: Significativo e não significativo respectivamente pelo teste $F$ a 5 \% de significância

Na serragem o melhor rendimento para 12 $\mathrm{h}$ de reação é encontrado na interação com ( $\left.\left[\mathrm{BMIM}^{+}\right]\left[\mathrm{BF}_{4}^{-}\right]\right)$. Quando o tempo de reação é de $24 \mathrm{~h}$ todas as interações são consideradas estatisticamente iguais. Com $48 \mathrm{~h}$ de reação a biomassa pré-tratada apresentou o melhor desempenho, o que se repete para $72 \mathrm{~h}$ de reação, ficando as outras quatro interações igualmente inferiores.

Quando se avaliam as três biomassas em conjunto para o mesmo tempo e mesma reação de hidrólise, a cana-de-açúcar apresenta melhor desempenho, excetuandose na interação com o ([BMIM $\left.\left.{ }^{+}\right]\left[\mathrm{Br}^{-}\right]\right)$em que a serragem obteve melhor resultado, fato que se repete na interação com ([BMIM $\left.{ }^{+}\right]$ $\left.\left[\mathrm{H}_{3} \mathrm{CCOO}\right]\right)$ em que a serragem se iguala a cana-de-açúcar. O melhor desempenho do capim-elefante foi observado para biomassa in natura, com exceção do tempo de $48 \mathrm{~h}$ de reação. 
Tabela 6. Médias de rendimento de glicose (\%) para os tempos de 12 a 72 h de hidrólise enzimática e as diferentes combinações de reação de hidrólise e biomassas

\section{QUADRO DE MÉDIAS}

\begin{tabular}{|c|c|c|c|c|c|c|c|c|c|c|c|c|c|c|c|c|c|c|c|c|}
\hline \multicolumn{21}{|c|}{ QUADRO DE MÉDIAS } \\
\hline & \multicolumn{4}{|c|}{ Sem pré-tratamento } & \multicolumn{4}{|c|}{ Com pré-tratamento } & \multicolumn{4}{|c|}{ Biomassa x BMIN Br } & \multicolumn{4}{|c|}{ Biomassa x BMIN Ac } & \multicolumn{4}{|c|}{ Biomassa x BMIN BF4 } \\
\hline & $12 \mathrm{~h}$ & $24 h$ & $48 h$ & $72 h$ & $12 \mathrm{~h}$ & $24 h$ & $48 h$ & $72 \mathrm{~h}$ & $12 \mathrm{~h}$ & $24 h$ & $48 h$ & $72 \mathrm{~h}$ & $12 \mathrm{~h}$ & $24 h$ & $48 h$ & $72 \mathrm{~h}$ & $12 \mathrm{~h}$ & $24 h$ & $48 h$ & $72 \mathrm{~h}$ \\
\hline \multirow{2}{*}{$\begin{array}{l}\text { Cana-de- } \\
\text { açúcar }\end{array}$} & 19,3 & 21,3 & 31,3 & 33,9 & 56,6 & 56,9 & 70,5 & 72,5 & 13,6 & 2,46 & 3,6 & 3,1 & 19,6 & 14,5 & 15,1 & 19 & 49,3 & 47,6 & 56,1 & 57,7 \\
\hline & $\mathrm{aC}$ & $\mathrm{aC}$ & $\mathrm{aC}$ & $\mathrm{aC}$ & $\mathrm{aA}$ & $\mathrm{aA}$ & $\mathrm{aA}$ & $\mathrm{aA}$ & $\mathrm{aC}$ & $\mathrm{bD}$ & $\mathrm{bE}$ & $\mathrm{bE}$ & $\mathrm{aC}$ & $\mathrm{aC}$ & $\mathrm{aD}$ & $\mathrm{aD}$ & $\mathrm{aB}$ & $\mathrm{aB}$ & $\mathrm{aB}$ & $\mathrm{aB}$ \\
\hline \multirow{2}{*}{$\begin{array}{l}\text { Capim- } \\
\text { elefante }\end{array}$} & 16,1 & 19,3 & 24,5 & 32,2 & 15,0 & 19,0 & 42,3 & 55,0 & 6,4 & 3,2 & 2,7 & 7,5 & 9,0 & 6,5 & 6,0 & 10,6 & 7,3 & 7,9 & 10,1 & 13,8 \\
\hline & $\mathrm{aA}$ & $\mathrm{aA}$ & $\mathrm{bB}$ & $\mathrm{aB}$ & $c A$ & $c A$ & $\mathrm{bA}$ & $\mathrm{bA}$ & $b B$ & $b B$ & $b c$ & $b c$ & $\mathrm{aB}$ & $b B$ & bC & $\mathrm{bC}$ & $c B$ & $c B$ & $\mathrm{cC}$ & $c C$ \\
\hline \multirow[t]{2}{*}{ Serragem } & 15,2 & 21,3 & 18,7 & 25,7 & 23,6 & 27,3 & 34,8 & 51,3 & 17,6 & 15,5 & 21,4 & 27,9 & 14,6 & 20,9 & 20,9 & 24,7 & 33,1 & 18,6 & 22,9 & 25,3 \\
\hline & $a B$ & $\mathrm{aA}$ & $\mathrm{bB}$ & $\mathrm{bB}$ & $b B$ & $\mathrm{bA}$ & $c A$ & $c A$ & $a B$ & $\mathrm{aA}$ & $\mathrm{aB}$ & $\mathrm{aB}$ & $\mathrm{aB}$ & $\mathrm{aA}$ & $\mathrm{aB}$ & $\mathrm{aB}$ & bA & bA & $\mathrm{bB}$ & $\mathrm{bB}$ \\
\hline
\end{tabular}

*Médias das diferentes combinações de reações de hidrólise enzimática dentro do mesmo tempo e da mesma biomassa seguidos pela mesma letra maiúscula na linha, pertencem ao mesmo grupo estatístico a $5 \%$ de significância pelo teste de Scott Knott; **Médias das diferentes biomassas dentro do mesmo tempo e da mesma reação de hidrólise enzimática seguidos pela mesma letra minúscula na coluna, pertencem ao mesmo grupo estatístico a $5 \%$ de significância pelo teste de Scott Knott 


\subsection{Regressão polinomial}

Para os modelos lineares o rendimento de glicose apresentou incremento linear em função do tempo de reação (Figura 1). Conforme o fabricante das enzimas, o tempo ótimo de reação é de $72 \mathrm{~h}$, sendo que transcorrido esse tempo a tendência é de saturação do meio, e a produção de glicose tende a diminuir.

Seguindo um modelo quadrático de resposta observou-se que para tais combinações com o tempo de $72 \mathrm{~h}$ de reação o rendimento de glicose tende a estabilizar (Figura 2).
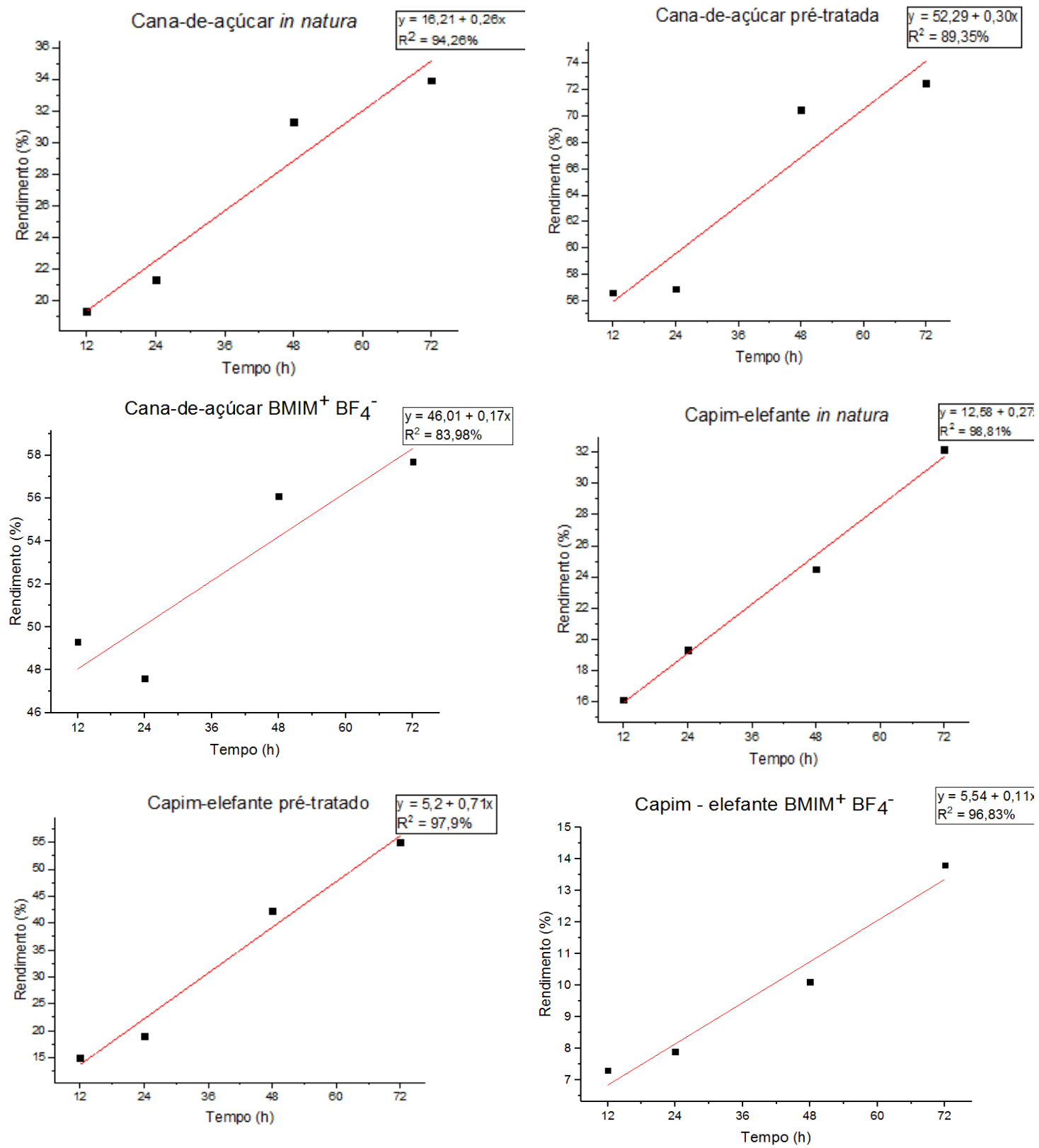

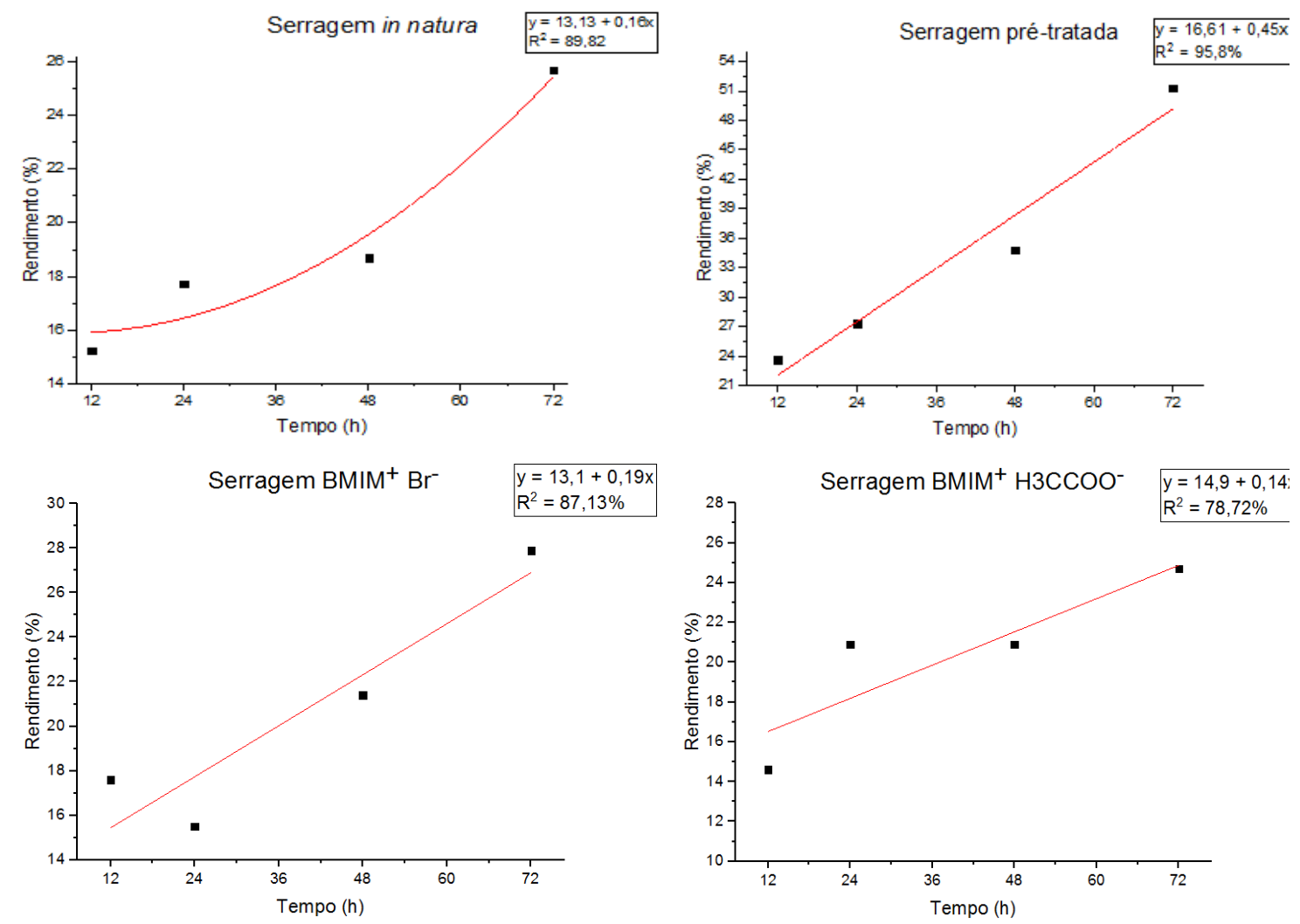

Figura 1. Rendimento médio de glicose em função das biomassas, reações de hidrólise e tempo com modelo linear de resposta. Significativo a $5 \%$ pelo teste $F$

Observa-se, nestes casos, que o tempo de reação de $12 \mathrm{~h}$ parece ser mais viável do que manter o processo hidrolítico por $72 \mathrm{~h}$, uma vez que não ocorre grande incremento no rendimento da hidrólise. Para a cana-deaçúcar e capim-elefante o comportamento do decaimento é parecido quando se utiliza os $\mathrm{LI}$ $\left(\left[\mathrm{BMIM}^{+}\right]\left[\mathrm{Br}^{-}\right]\right)$e $\left(\left[\mathrm{BMIM}^{+}\right]\left[\mathrm{H}_{3} \mathrm{CCOO}^{-}\right]\right)$. Para a serragem o decaimento ocorre com a interação do $\mathrm{LI}\left(\left[\mathrm{BMIM}^{+}\right]\left[\mathrm{BF}_{4}^{-}\right]\right)$.

$\mathrm{O}$ fato da concentração de glicose ser alta em $12 \mathrm{~h}$ de reação, decair com 24 e $48 \mathrm{~h}$ e voltar a crescer próximo a $72 \mathrm{~h}$ como pode ser observado em alguns gráficos provavelmente está relacionado com a inibição da enzima, que acontece naturalmente quando o meio reacional já está com uma determinada concentração de glicose (glicose essa produzida pela própria enzima na hidrólise da celulose). Fato relevante a se destacar é que a enzima sofre inibição pela alta concentração dos produtos produzidos por ela mesma, ou seja, quando a concentração de glicose no meio reacional começa a se elevar, a $\beta$ glucosidase começa a inativar. ${ }^{28}$

Algumas pesquisas apontam que com concentrações menores de $\mathrm{LI}$ os resultados referente à quantificação de glicose podem apresentar melhoras, ou seja, quanto menor a quantidade de $\mathrm{LI}$ melhor será o rendimento, ${ }^{29}$ podendo-se atribuir o fato da quantificação menor de glicose em reações com a presença dos LI e sua atuação na desnaturação das enzimas.

Embora diversas publicações apontem para o fato de que o uso de enzimas em LI favorece o aumento da atividade enzimática quando comparado aos solventes orgânicos convencionais (que inibem a atividade catalítica), ${ }^{5}$ o observado no presente trabalho foi que a ação dos LI não promoveram a melhora da ação catalítica da enzima, fato que se repete em outras pesquisas, que apontam que a atividade enzimática diminuiu com concentrações crescentes de LI. ${ }^{28}$ 

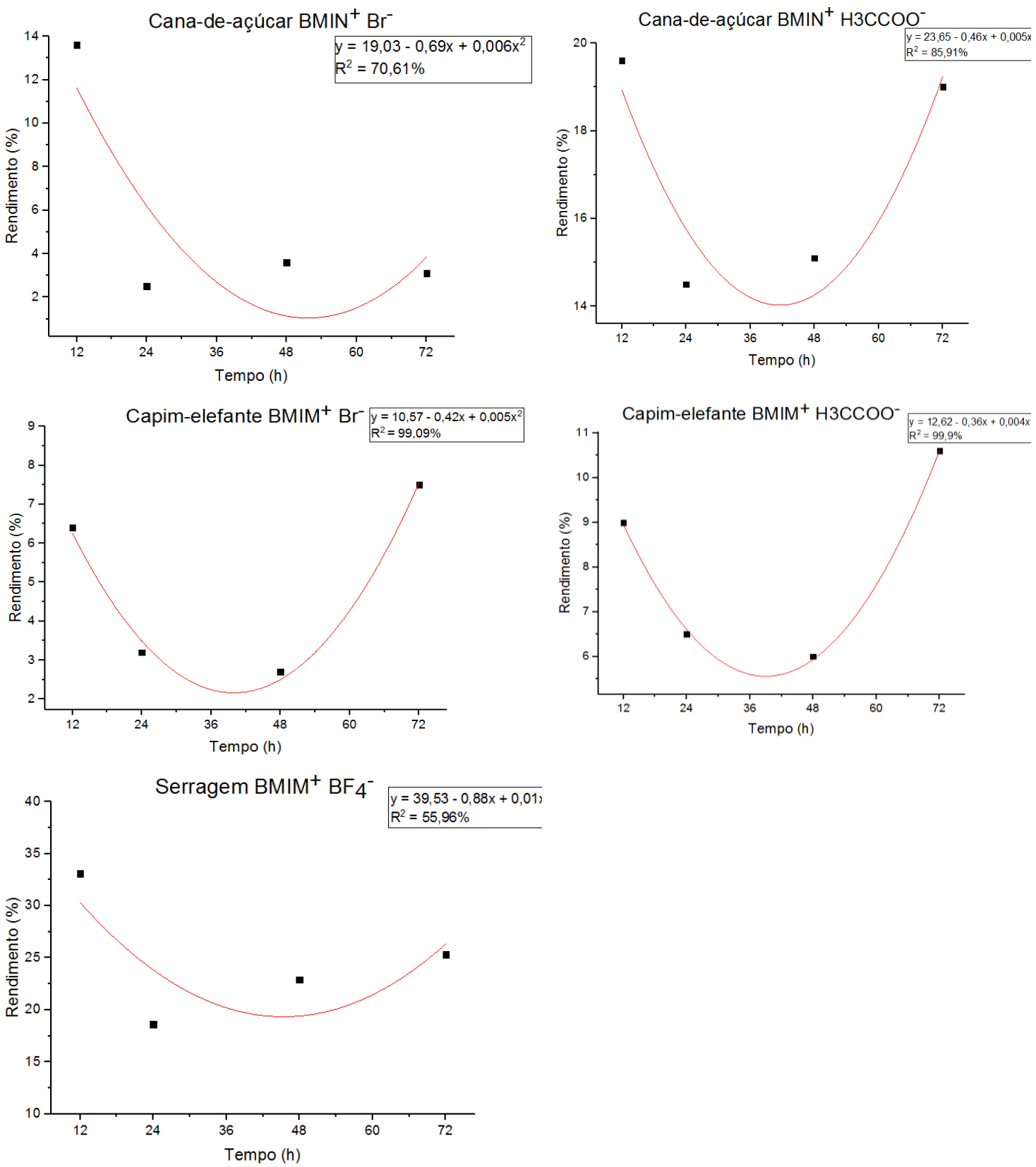

Figura 2. Rendimento médio de glicose em função das biomassas, reações de hidrólise e tempo com modelo quadrático de resposta. Significativo a $5 \%$ pelo teste $\mathrm{F}$

Observa-se ainda a necessidade de se estudar mais profundamente as interações entre as enzimas e os Lls e quais condições podem facilitar o processo catalítico e o rendimento na hidrólise enzimática, como relação de volume de $\mathrm{LI}$ a ser aplicado na reação.
Mesmo tendo acesso a todas essas informações é difícil afirmar com precisão o comportamento das enzimas em $\mathrm{LI}$, pois são materiais que começaram a ser estudados mais a fundo a pouco tempo (últimas duas décadas). A presença de íons em solução tem efeito direto na estabilidade da enzima, podendo ser benéfico ou prejudicial à sua estabilidade catalítica, dessa forma com os 
dados fornecidos por esse experimento é possível concluir que os $\mathrm{LI}$ empregados não facilitaram o acesso da enzima à celulose, ou seja, sua composição contendo um cátion volumoso (imidazol) não foi capaz de acessar os interstícios da biomassa por serem grandes.

Por todos estes motivos, a combinação de LIs e enzimas permite que se possa vislumbrar um futuro energético mais limpo e sem todos os problemas comumente associados nas diferentes formas de catálise, principalmente a ácida e a básica. Sem dúvida, a utilização dos LI para processos enzimáticos é extremamente promissora, apesar de ainda existirem muitos impedimentos tecnológicos associados a tais processos. ${ }^{5}$

\section{Conclusão}

O melhor desempenho para o rendimento da hidrólise foi o da cana-de-açúcar pré tratada, sem interação com os LIs (72,5\%). O LI mais promissor foi o $\left(\left[\mathrm{BMIM}^{+}\right]\left[\mathrm{BF}_{4}\right]\right)$ na interação com a cana-de-açúcar e $72 \mathrm{~h}$ de reação com rendimento de $57,7 \%$.

De modo geral, pode-se concluir que sob as condições apresentadas no presente estudo, o uso de tais Lis não aumentou o rendimento da hidrólise enzimática. A características dos ânions presentes nos LIs, e suas interações com as enzimas, diminuíram a capacidade de catálise. Apesar disto os Lls, pelas suas características de baixa toxicidade, são um meio promissor para novos testes catalíticos nas reações de hidrólise de celulose. Isto fica evidenciado quando analisamos a atuação dos Lls em baixos tempos de reação.

\section{Referências Bibliográficas}

\footnotetext{
${ }^{1}$ Magro, F. G.; Decesaro, A.; Berticelli, R.; Colla, M. L. Bioethanol Production Using Microalgae: A review. Semina: Ciências Exatas e Tecnológicas 2016, 37, 159. [CrossRef]
}

${ }^{2}$ Mosier, N.; Wyman, C.; Dale, B.; Elander, R.; Lee, Y. Y.; Holtzapple, M.; Ladish, M. Features of promising technologies for pretreatment of lignocellulosic biomass. Bioresource Technology 2005, 96, 673. [CrossRef]

${ }^{3}$ Santos, F. A.; Queiroz, J. H.; Colodette, J. L.; Manfredi, M.; Queiroz, M. E. L. R.; Caldas, C. S.; Soares, F. E. F. Otimização do prétratamento hidrotérmico da palha de cana-deaçúcar visando à produção de etanol celulósico. Quimica Nova 2014, 96, 673. [CrossRef]

${ }^{4}$ Santiago, B. L. S.; Rodrigues, F. A. Processamento de biomassa lignocelulósica para produção de etanol: Uma revisão. The Journal of Engineering and Exact Sciences 2017, 3, 1011. [CrossRef]

${ }^{5}$ Medeiros, G. A.; Gonçalves, S. B.; Rodrigues, D. S.; Neto, B. A. D. Enzimas e líquidos iônicos: Uma combinação promissora para um biodiesel limpo. Revista Virtual de Química 2013, 5, 74. [CrossRef]

${ }^{6}$ Rantwijk, F.; Sheldon, R. A. Biocatalysis in ionic liquid. Chemical Reviews 2007, 107, 2757. [Link]

${ }^{7}$ Lai, J.; Hu, Z.; Wang, P.; Yang, Z. Enzymatic production of microalgal biodiesel in ionic liquid [BMIm][PF6]. Fuel 2012, 95, 329. [CrossRef]

${ }^{8}$ Morais, J. P. S.; Rosa, M. de F.; Marconcini, J. M.; Procedimentos para análise Lignocelulósica, Centro Nacional de Pesquisa do Algodão: Campina Grande, 2010.

${ }^{9}$ Rodrigues, R. C.; Métodos de análise bromatológica de alimentos: métodos físicos, químicos e bromatológicos, Embrapa: Pelotas, 2010.

${ }^{10}$ Pinto, B.; Calloni, G.; Silva, S. A.; Revista Liberato 2013, 14, 1. [Link]

${ }^{11}$ Menezes, T. J. B.; Hennies, P. T. Influência do pré-tratamento do bagaço de cana-deaçúcar com peróxido alcalino e hidróxido de sódio no sistema celulolítico de $A$. níger. Coletânea Ital 1991, 21, 213.

${ }^{12}$ Souza, D. A.; Trabalho de Conclusão de Curso, Universidade Federal do Tocantins, Brasil, 2014. [Link] 
${ }^{13}$ Lu, J.; Li, X.; Zhao, J.; Qu, Y. Enzymatic Saccharification and Ethanol Fermentation of Reed Pretreated with Liquid HotWater. Journal of Biomedicine and Biotechnology 2013, 144, 539. [CrossRef]

${ }^{14}$ Oliveira, F. M. V.; Dissertação de mestrado, Universidade de São Paulo, Brasil, 2010. [Link]

${ }^{15}$ Ogeda, T. L.; Petri, D. F. S. Hidrólise enzimática de biomassa. Química. Nova 2010, 33, 1549. [CrossRef]

${ }^{16}$ Boonstra, M. J.; Tjeerdsma, B. Chemical analysis of heat treated softwoods. European Journal of Wood and Wood Products. 2006, 64, 204. [Link]

17 Li, J.; Henriksson, G.; Gellerstedt, G. Carbohydrate reactions during hightemperature steam treatment of aspen wood. Applied Biochemistry Biotechnology 2005, 125, 175. [Link]

${ }^{18}$ Pandey, A.; Soccol, C. R.; Nigam, P.; Soccol, $\mathrm{V}$. T. Biotechnological potential of agroindustrial residues. I: sugarcane baggase. Bioresource Technology 2000, 74, 69. [CrossRef]

${ }^{19}$ Alkasrawi, M.; Eriksson, T.; Börjesson, J.; Wingren, A.; Galbe, M.; Tjernedld, F.; Zacchi, $G$. The effect of Tween-20 on simultaneous saccharification and fermentation of softwood to ethanol. Enzyme and Microbial Technology 2003, 33, 71. [CrossRef]

${ }^{20}$ Gonçalves, A. R.; Moriya, R. Y.; Oliveira, L. R.; Saad, M. B. Xylanase recycling for the economical biobleaching of sugarcane bagasse and straw pulps. Enzyme and
Microbial Technology 2008, 43, 157. [CrossRef]

${ }^{21}$ Barbosa, L. C.; Pedrazzi, C. P.; Ferreira, E. S.; Schneid, G. N.; Wille, V, K. D. Avaliação dos resíduos de uma serraria para a produção de celulose kraft. Ciência Florestal 2014, 24, 491. [CrossRef]

${ }^{22}$ Mainieri, C.; Chimelo, J. P.; Divisão de Madeiras: Fichas de características das madeiras brasileiras, Instituto de Pesquisas Tecnológicas: São Paulo, 1990.

${ }^{23}$ Leite, R.M.B; Filho, J. L. Q.; Silva, D. S. Produção e valor nutritivo do capim-elefante cultivar Cameroon em diferentes idades. Agropecuária Técnica 2000, 21, 1. [Link]

${ }^{24}$ Santos, E. A.; Silva, D. S.; Filho, J. L. Q. Composição Química do Capim-Elefante cv. Roxo cortado em diferentes alturas. Revista Brasileira de Zootecnia 2001, 30, 18. [CrossRef]

${ }^{25}$ Castro, J. P.; Dissertação de Mestrado, Universidade Federal de Lavras, Brasil, 2012. [Link]

${ }^{26}$ Hamelinck, C.N.; Van Hooijdonk, G.; Faaij, A.P.C. Ethanol from lignocellulosic biomass: techno-economic performance in short-, middle-and long-term. Biomass and Bioenergy 2005, 28, 384. [CrossRef]

${ }^{27}$ Bubner, P.; Plank, H.; Nidetzky, B. Visualizing cellulose activity. Biotechnology and Bioengineering 2013, 110, 1529. [Link]

${ }^{28}$ Medeiros, G., A.; Dissertação de Mestrado, Universidade de Brasília, Brasil, 2014. [Link] 